\title{
Genetic diversity of seeds from four German Douglas fir (Pseudotsuga menziesii) seed orchards
}

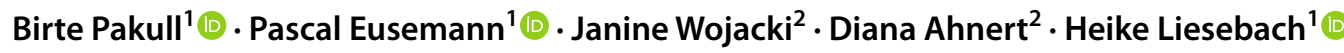

Received: 24 February 2021 / Revised: 9 September 2021 / Accepted: 17 September 2021 / Published online: 30 September 2021

(c) The Author(s) 2021

\begin{abstract}
In Germany, Douglas fir (Pseudotsuga menziesii Franco) is seen as a valuable species for future cultivation in times of climate change. Local seed production in seed stands and seed orchards may secure that local adaptation is transferred to the next generation, but small population sizes could lower genetic diversity and thus future adaptability. Here we analyse the transfer of genetic diversity from parent to offspring generation in four older German seed orchards. We detected low pollen contamination rates due to high levels of spatial isolation. Even with a relatively low number of 40 clones, seed orchard design with randomized and repeated planting of clones led to low selfing rates, and despite uneven parental contributions, the number of successful parents and the level of genetic intermixture were high enough to allow the transfer of an adequate part of the genetic diversity to the next generation. Larger numbers, however, might be needed to reliably conserve the entire genetic diversity over succeeding generations. Conclusions on the establishment of future seed orchards and regarding areas requiring further research are drawn at the end of the paper.
\end{abstract}

Keywords Douglas fir $\cdot$ Seed orchard $\cdot$ Forest reproductive material (FRM) $\cdot$ Genetic diversity

\section{Introduction}

Douglas fir (Pseudotsuga menziesii Franco), a conifer native to western North America, was introduced to Europe about 190 years ago (Lavender and Hermann 2014). Two different varieties of Douglas fir have been described, the coastalso-called "green"- variety [Pseudotsuga menziesii var. menziesii (Mirbel) Franco] growing on the North American Pacific Coast, and the inland-so-called "blue"- [Pseudotsuga menziesii var. glauca (Mayr) Franco] variety (Lavender and Hermann 2014). A third intermediate variety the socalled "grey" or Fraser River Douglas fir [Pseudotsuga menziesii var. caesia (Schwer.) Franco], has been described but is not commonly accepted (Kleinschmit and Bastien 1992; Spellmann et al. 2015).

Communicated by Oliver Gailing.

Birte Pakull

birte.pakull@thuenen.de

1 Thünen Institute of Forest Genetics, Sieker Landstr. 2, 22927 Großhansdorf, Germany

2 Thünen Institute of Forest Genetics, Eberswalder Chaussee 3a, 15377 Waldsieversdorf, Germany
In Germany, Douglas fir is seen as valuable for future cultivation since it represents a high-performing species with good adaptive potential to future climatic conditions and can be integrated into local ecosystems (Spellmann et al. 2015). Today, Douglas fir covers about $2 \%$ of the German forest areas and therefore represents the most frequent non-native forest tree species in Germany (Riedel et al. 2017). Most of the Douglas fir growing in Germany belongs to the coastal "green" variety, which performed better in European provenance field tests (Kleinschmit and Bastien 1992; Spellmann et al. 2015).

In recent times, nearly all Douglas fir seed traded and planted in Germany is produced in domestic approved seed stands and seed orchards (Anonymous 2021). The local production of seeds within Germany has the advantage that potential previous local adaptation is transferred to the next generation. On the other hand, many of the German Douglas fir seed stands are comparatively small and only barely fulfil the minimum requirements of 40 adult trees per approved seed stand stated in the German Act on Forest Reproductive Material and associated regularities (Anonymous 2002a,b). This could lead to potential consequences for the genetic diversity of the produced seeds. Genetic diversity is one of the key features that allow species to evolve and adapt to 
changing environments. Therefore a high level of genetic diversity in produced seeds is crucial for the formation of adaptive future stands, able to cope with the challenges of global climate change, pollution and new pathogens (White et al. 2007). Moreover, small population sizes also lead to increased selfing rates (again promoting a potential loss of genetic diversity) and inbreeding depression effects like higher levels of empty seeds (e.g. Woods and Heaman 1989) or lower levels of vitality and seedling survival. Accordingly, Wojacki et al. (2019) were able to show loss of genetic diversity and increasing rates of selfing and empty seeds within seeds produced in small and isolated artificial Douglas fir seed stands.

However, while seed stands are natural or artificial populations which have been approved for seed production, seed orchards are plantations of a certain limited number of selected trees with superior phenotypical traits in various numbers of ramets per clone. The number of selected clones in seed orchards varies but is often much lower than the number of individual parent trees in seed stands. Anyway, the high number of individual trees including repeated genotypes due to multiple ramets per clone, combined with the designed planting scheme, aims to promote a better genetic intermixture based on a higher number of different parent combinations.

For seed orchard design and setup, two conflicting aims have to be considered (reviewed in Funda and El-Kassaby 2012). To fulfil commercial needs, only trees featuring the best phenotypic traits should be selected and their reproduction should be facilitated for the production of genetically improved seed. Pollen inflow from outside of the seed orchard may introduce inferior genetic material and should be minimized. On the other hand, high quality commercially traded seeds should not only inherit selected phenotypic traits but also include a preferably high level of genetic diversity, to enable the formation of adaptive and sustainable future stands able to survive under the conditions of global climate change (Ingvarsson and Dahlberg 2019; Ivetic et al. 2016). For this reason, seed orchards should contain a certain minimum number of different, ideally unrelated clones. Selfing and mating between relatives should be minimized since it facilitates the loss of genetic diversity while inbreeding depression might at the same time lead to fitness reduction of the progeny.

Here we analyse parent and offspring generation of four older German Douglas fir seed orchards, differing in number of clones and number of ramets per clone. Since no comprehensive data about phenotypical and breeding values are available, this study is focussed on population genetic analyses and the conservation of genetic diversity. By analysing genetic diversity parameters in parent and offspring generation and determining selfing and pollen contamination rates and the participation of the different parent clones in reproduction the conservation of genetic diversity over the generations can be assessed. Comparing the results with similar analyses from approved seed stands and other seed orchards will allow conclusions to be drawn for the future design of seed orchards for the production of adequate genetically diverse seeds of Douglas fir. Besides theoretical and population genetic aspects of seed orchard designs (reviewed by Liesebach et al. 2021), such experimental data on older existing seed orchards should support pending decisions for the establishment of new seed orchards in Germany. Furthermore, these results will be a basis for the evaluation of current harvesting practices and can, if necessary, help in adjusting these from a genetic perspective.

\section{Material and methods}

\section{Plant material}

A total of four open-pollinated seed orchards located in different regions of Germany were used for genetic analysis. Table 1 summarizes the characteristics of the four seed orchards.

The clones of the seed orchard Voigtsdorf [seed orchard (SO) GREEN1] belong to the coastal "green" variety and were selected in the German Douglas fir stand Kiekindemark, for which an origin in the region Humptulips (Olympic Peninsula, Washington, USA) is assumed. The clones of the seed orchards Niederfinow (SO GREEN2) and Harsefeld (SO GREEN3) were selected from progenies of the coastal variety growing in older German Douglas fir provenance tests, primarily also originating from populations in the region Humptulips on the Olympic Peninsula, Washington, USA. This provenance is generally known for good performance in German field tests (Rau 2005; Weller and Jansen 2017). The seed orchard in Beerwalde (SO GREY) was declared to consist of the intermediate "grey" Douglas fir, its clones were selected within the German stand "Schindelbach" located in Saxony (Germany). The North American origin of this stand is unknown.

For genetic analysis of the parent/adult generations, all available adult clones were sampled, if possible. When no current planting scheme of the seed orchard was available (SO GREY), all remaining adult trees $(N=300$ for SO GREY) were sampled and clones were identified during genetic analysis. For the seed orchards GREEN1, GREEN2 and GREY, more clones than originally stated were identified. Some of these genotypes were only present as one single individual without identical ramets and probably represent overgrowing rootstocks that were sampled. These individuals were not excluded from genetic analysis, since they might have participated in the production of the analysed offspring generation. 
Table 1 Characteristics of the four analysed seed orchards

\begin{tabular}{|c|c|c|c|c|c|c|c|c|c|}
\hline Seed orchard & Location & State & $\begin{array}{l}\text { Geographic } \\
\text { coordinates } \\
\left({ }^{\circ}\right)\end{array}$ & Size (ha) & $\begin{array}{l}\text { Age at time } \\
\text { of sampling } \\
\text { (years) }\end{array}$ & Origin & $\begin{array}{l}\text { Number } \\
\text { of clones } \\
\text { (stated/deter- } \\
\text { mined) }\end{array}$ & $\begin{array}{l}\text { Analyzed } \\
\text { offspring }\end{array}$ & $\begin{array}{l}\text { Offspring with } \\
\text { known seed } \\
\text { parent }\end{array}$ \\
\hline GREEN1 & Voigtsdorf & $\begin{array}{l}\text { Mecklen- } \\
\text { burg-West } \\
\text { Pomerania }\end{array}$ & $\begin{array}{c}\text { N } 53.47 \mathrm{E} \\
11.88\end{array}$ & 1.0 & 52 & $\begin{array}{l}\text { Kiekin- } \\
\text { demark } \\
\text { (coastal } \\
\text { variety) }\end{array}$ & $16 / 25$ & 44 & - \\
\hline GREEN2 & Niederfinow & Brandenburg & $\begin{array}{c}\text { N } 52.84 \mathrm{E} \\
13.93\end{array}$ & 2.2 & 28 & $\begin{array}{l}\text { Humptulips } \\
\text { (coastal } \\
\text { variety) }\end{array}$ & $37 / 40$ & 281 & $\begin{array}{l}281 \text { (30 seed } \\
\text { parents) }\end{array}$ \\
\hline GREEN3 & Harsefeld & $\begin{array}{l}\text { Lower } \\
\text { Saxony }\end{array}$ & $\begin{array}{l}\text { N } 53.45 \mathrm{E} \\
9.54\end{array}$ & 2.8 & 39 & $\begin{array}{l}\text { Humptulips } \\
\text { (coastal } \\
\text { variety) }\end{array}$ & $125 / 115$ & 365 & - \\
\hline GREY & Beerwalde & Saxony & $\begin{array}{c}\text { N } 50.88 \mathrm{E} \\
13.56\end{array}$ & 2.3 & 32 & $\begin{array}{l}\text { Schindelbach } \\
\text { ("grey" } \\
\text { variety) }\end{array}$ & $30 / 32$ & 686 & $\begin{array}{l}387 \text { (39 seed } \\
\text { parents) }\end{array}$ \\
\hline
\end{tabular}

Genetic analysis of the offspring generation was based on seed or seedling data. No seeds were available for SO GREEN1. Young plants from recent afforestation planted nearby were analysed instead. Unfortunately, about threequarters of these plants proved to be of unknown origin. Only 44 individuals descending from the adult clones of the seed orchard were identified. Seed collection in SO GREEN2 was carried out manually, with the aim of sampling equal numbers of seeds from all available seed-bearing clones. For SO GREEN3 seedlings from a nursery originating from a commercial harvest of the seed orchard were analysed. For SO GREY, seed collection from individual adult trees was carried out manually (387 seeds). Since no current planting scheme of the seed orchard was available, a large number of seed-bearing trees $(N=39)$ was sampled. Additionally, seeds from a mixed seed lot of a commercial harvest of the seed orchard were analysed (299 seeds). Table 1 gives an overview of the number of adult clones and analysed offspring individuals for each seed orchard.

\section{DNA extraction and SSR marker analysis}

DNA from individual trees was extracted from needle or cambium samples according to the protocol of Dumolin et al. (1995). Embryos extracted from the seeds were used for seed DNA extraction. Genotyping was carried out as described in Wojacki et al. (2019), using 9 highly polymorphic microsatellite (SSR) markers (Slavov et al. 2004, PmOSU3D5, PmOsu4A7; PmOsu3B2, PmOSu1F9, PmOSU2G12, PmOSU3G9, PmOSU3F1, PmOSU3B9 and PmOSU2D4) in two multiplex sets. The software GeneMarker V3.0.0 (SoftGenetics LLC, State College, PA, USA) was used for allele calling.

\section{Data analysis}

The reliability of the marker set was evaluated by calculating so-called combined non-exclusion probabilities using CERVUS Version 3.0.7 (Kalinowski et al. 2007; Marshall et al. 1998). These probabilities were calculated for populations in Hardy-Weinberg equilibrium but can give an estimate for pedigree assignments perchance.

For the comparison of the genetic structures of the different seed orchards, we used the software STRUCTURE (Pritchard et al. 2000). The mean membership coefficients for $K=1$ to $K=10$ at 20 runs per $K$ were calculated, using the following parameters: admixture model, correlated allele frequencies, 20,000 burnin replications, 20,000 MCM replications after burnin. The results of each of the 20 runs per $K$ were merged using the web tool CLUMPAK (Kopelman et al. 2015). The optimal number of genetic clusters was estimated with the $\Delta K$ method described in Evanno et al. (2005). The webtool StructureHarvester (Earl 2012) was used for determination of the maximum $\Delta K$.

The software COLONY (Version 2.0.6.5, Jones and Wang 2010) was used for pedigree reconstruction, identification of full and half sibships, genotype reconstruction of unsampled parents and determination of a sibship based effective population size $(\mathrm{Ne})$ under random and non-random mating models. Pedigree reconstruction with known maternal sibship was used for offspring of single tree-wise harvests. Rates of dropouts/null alleles and mistyping were estimated by COLONY and adjusted separately for each seed orchard. Analyses were run using the following parameters: female and male polygamy, monoecious and diploid species, length of run: medium, analysis method: FL-PLS combined (FL: full likelihood, PLS: pairwise-likelihood score), weak prior. All other parameters were set to default. For each seed orchard, 
the final analysis was repeated three times with different random seed numbers to verify the results. For an estimation of the potential degree of relatedness of the parental clones of the different seed orchards, a COLONY analysis including only the adult genotypes as theoretical offspring of an unknown parent population was performed.

For the estimation of genetic diversity the observed and expected heterozygosity, the mean number of alleles per locus (A) and the mean effective number of alleles (Ae), a value that is mainly based on the allele frequency distribution of more common alleles, were calculated for each generation and each seed orchard separately using GenAlEx (Peakall and Smouse 2012). Allelic Richness, a commonly used parameter that compensates for different sample sizes was calculated with SAS (SAS 9.4 TS Level 1M5 X64_10PRO platform (Version 9.4), Copyright (c) 2016 by SAS Institute Inc., Cary, NC, USA: proc survey select, proc allele, proc means). Rarefaction was carried out with resampling individuals without replacement and 1000 replicates. All other statistical analyses were performed using R 3.6.3 (RCoreTeam 2013).

\section{Results and discussion}

\section{Clone composition of the seed orchards (adult generation)}

STRUCTURE analysis of all parental clones (Fig. 1B) of the four seed orchards showed a clear separation between SO GREY and the other three seed orchards at $K=2$ (see Fig. 1A for graphic display of maximum $\Delta K$ ). The divergent individual in the seed orchard GREEN2 represents one of the individuals with unique genotypes probably originating from overgrowing rootstock. The clear separation between the seed orchards runs along the stated origins/varieties of the seed orchards. SO GREY was stated to represent the "grey" variety, while all other seed orchards consist of the coastal "green" variety and originate from the region
Humptulips. A second hierarchic STRUCTURE analysis using only the parental clones of the three coastal "green" Douglas fir seed orchards showed no further differentiation between the seed orchards (data not shown). This can be explained by the common region of origin of these three seed orchards.

For optimal genetic diversity, seed orchards should ideally consist of unrelated clones. To allow a rough estimation of the level of relatedness of the parental clones within the analysed seed orchards, a COLONY analysis including only the adult generation as theoretical offspring of an unknown parent population was performed. This analysis was carried out for each seed orchard separately and for a combination of all four seed orchards. Table 2 shows an overview of the results of the analyses for each seed orchard.

Discovering relationships might be much more reliable when working with known parent populations and using larger sample sizes and a higher amount of markers (compare Harrison et al. 2013). The assumption that the used clones are the offspring of a common parent population is highly hypothetical. For this reason, this analysis can only give a very rough estimation of potential relatedness. However, in the three seed orchards with relatively low clone numbers (SO GREEN1, GREEN2 and GREY), differences in the degree of relatedness were detected. The adult trees of the seed orchard GREY seem to feature a higher degree of relatedness than those of the two seed orchards GREEN1 and GREEN2. SO GREY shows high levels of potential fullsib and half-sib relations. 23 clones out of 32 were assigned to a single reproductive unit/cluster (here defined as a group of related individuals sharing the same parents). The 115 clones of SO GREEN3 also show higher levels of potential full-sib and half-sib relations, 98 of the 115 adult clones assign to only 6 different reproductive units, with the biggest reproductive unit including 38 clones. However, this can, to a certain degree, be explained by the higher number of different clones.

When the parent clones of all four seed orchards are analysed together, COLONY identifies potential full- and
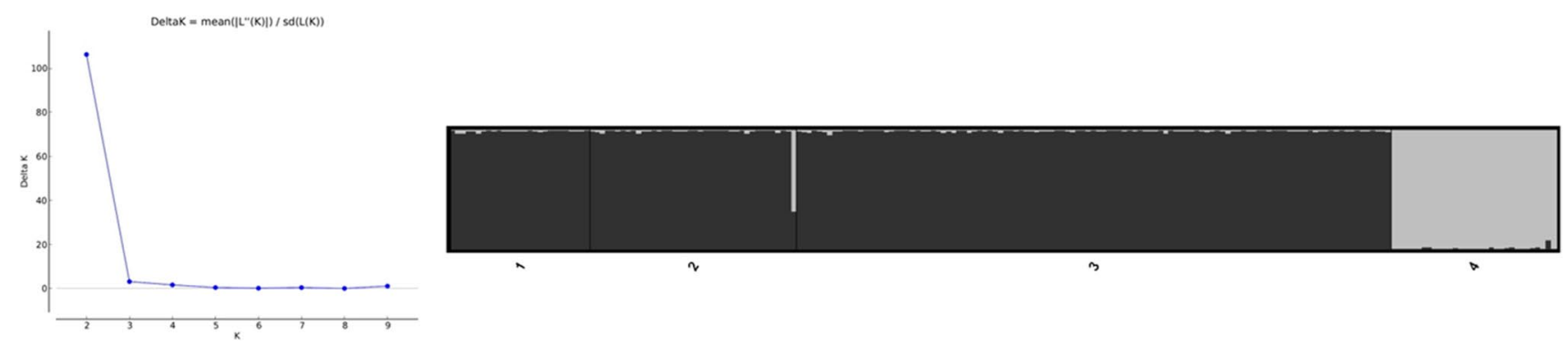

Fig. 1 STRUCTURE analysis: A $\Delta K$ for $K 2-9$, B mean membership coefficients for $K=2,20$ runs merged with CLUMPAK (Kopelman et al. 2015). Individuals are sorted according to seed orchard:
1: SO GREEN1 (Voigtsdorf), 2: SO GREEN2 (Niederfinow), 3: SO GREEN3 (Harsefeld), 4: SO GREY (Beerwalde) 
Table 2 Potential degree of relatedness of the parental clones of the different seed orchards

\begin{tabular}{|c|c|c|c|c|c|c|c|c|}
\hline Location & Seed orchard & No. of clones & $\begin{array}{l}\text { No. of clusters/ } \\
\text { reproductive } \\
\text { units within } \\
\text { parental clones }\end{array}$ & $\begin{array}{l}\text { Average no. of } \\
\text { individuals per } \\
\text { cluster/repro- } \\
\text { ductive unit }\end{array}$ & $\begin{array}{l}\text { No. of individu- } \\
\text { als in biggest } \\
\text { cluster/repro- } \\
\text { ductive unit }\end{array}$ & $\begin{array}{l}\text { No. of } \\
\text { full-sib } \\
\text { relations }\end{array}$ & $\begin{array}{l}\text { No. of half- } \\
\text { sib relations }\end{array}$ & $\begin{array}{l}\text { No. of recon- } \\
\text { structed theo- } \\
\text { retical parents }\end{array}$ \\
\hline Voigtsdorf & GREEN1 & 25 & 18 & 1.4 & 5 & 3 & 12 & 36 \\
\hline Niederfinow & GREEN2 & 40 & 20 & 2.0 & 11 & 2 & 25 & 50 \\
\hline Harsefeld & GREEN3 & 115 & 17 & 6.8 & 38 & 6 & 158 & 106 \\
\hline Beerwalde & GREY & 32 & 5 & 6.4 & 23 & 11 & 151 & 27 \\
\hline
\end{tabular}

half-sib relations between parental clones of the three coastal "green" Douglas fir seed orchards, probably due to the common origin (Humptulips) of all parent clones. No potential full- and half-sib relations between the coastal "green" and the "grey" Douglas fir seed orchards were identified.

\section{Pedigree reconstruction}

Table 3 shows an overview of the results for the pedigree reconstruction for parental (adult trees) and offspring (seeds/ seedlings) generations. Low combined non-exclusion probabilities for parent pairs of $1.3 \times 10^{-12}, 5.8 \times 10^{-14}, 2.4 \times 10^{-14}$ and $5.7 \times 10^{-11}$ for the seed orchard GREEN1, GREEN2, GREEN3 and GREY, respectively, prove high reliability of the results.

For a large majority of offspring individuals from the different analysed seed orchards, both parents were clones located within the respective seed orchard (Table 3). For SO GREEN1 only 44 offspring individuals were analysed. The vast majority of them (42 individuals) originated from one single-parent clone. The low number of offspring individuals and the strongly distorted parentage proportions make further statistical analysis of the offspring of this seed orchard difficult. Therefore, the offspring generation of this seed orchard was excluded from further analysis.

For both seed orchards with single tree seed harvest (SO GREEN2 and 387 seeds of SO GREY), pedigree reconstruction allowed the assignment of the vast majority of the offspring individuals to the expected mother clone/seed parent
(SO GREEN2: 96.8\%, SO GREY: 97.4\%). A few deviations can be explained with mistakes in either sample handling, genotyping or within the available seed orchard planting scheme.

Sampling of different clones as seed parents proved to be uneven. The 32 trees used for single tree seed harvest in SO GREEN2 corresponded to 30 different genotypes/clones. Ten out of 40 clones were not sampled as seed parents. From the remaining 30 clones, two clones were sampled twice as two different ramets. A total of 4 to 18 offspring individuals per clone were analysed. Within SO GREY, harvest bias was even stronger. The 39 trees used for seed sampling corresponded to 18 different genotypes/clones. Of the 32 clones of this seed orchard, 14 were not sampled as seed parents at all, 7 clones were sampled once, for 4 clones 2 ramets were sampled, for 5 clones 3 ramets were sampled, and 4 and 5 ramets have been sampled for one clone each. A total of 10 to 50 offspring individuals per clone were analysed.

\section{Genetic diversity of the seed orchards}

Table 4 summarizes the results of the analysis of genetic diversity parameters. For all analysed seed orchards in both generations observed heterozygosity is lower than expected heterozygosity. This is probably due to the occurrence of null alleles and allele dropouts, leading to certain individuals being scored as false homozygotes. Null alleles could be confirmed for most of the markers during marker analysis of seed parents and their known offspring. However, COLONY
Table 3 Results of the pedigree reconstruction

\begin{tabular}{lllll}
\hline Location & Voigtsdorf & Niederfinow & Harsefeld & Beerwalde \\
\hline Seed orchard & GREEN1 & GREEN2 & GREEN3 & GREY \\
No. of clones & 25 & 40 & 115 & 32 \\
No. of offspring individuals & 44 & 281 & 365 & 686 \\
Offspring with assigned parent pair $p>0.95(\%)$ & $\mathrm{n} / \mathrm{a}$ & 100 & 100 & 98.68 \\
Outcrossed offspring, pollinated within stand (\%) & $\mathrm{n} / \mathrm{a}$ & 94.66 & 89.86 & 96.21 \\
Outcrossed offspring, pollinated from outside (\%) & $\mathrm{n} / \mathrm{a}$ & 3.56 & 8.49 & 0.58 \\
Selfed offspring individuals $(\%)$ & $\mathrm{n} / \mathrm{a}$ & 1.78 & 0.82 & 1.9 \\
No. of successful parents within the stand & $\mathrm{n} / \mathrm{a}$ & 34 & 88 & 29 \\
Estimated number of pollinators from outside & $\mathrm{n} / \mathrm{a}$ & 3 & 11 & 2 \\
\hline
\end{tabular}


Table 4 Genetic diversity parameters of the analysed seed orchards, $\mathrm{P}=$ parental generation, $\mathrm{F} 1=$ offspring generation

\begin{tabular}{|c|c|c|c|c|c|c|c|c|c|}
\hline Location & Seed orchard & $\begin{array}{l}\text { No. of } \\
\text { individuals } \\
(\mathrm{N})\end{array}$ & $\begin{array}{l}\text { Observed } \\
\text { heterozygo- } \\
\text { sity (Ho) }\end{array}$ & $\begin{array}{l}\text { Expected } \\
\text { heterozygo- } \\
\text { sity }(\mathrm{He})\end{array}$ & $\begin{array}{l}\text { Mean num- } \\
\text { ber of alleles } \\
\text { (A) }\end{array}$ & $\begin{array}{l}\text { Effective } \\
\text { number of } \\
\text { alleles (Ae) }\end{array}$ & $\begin{array}{l}\text { Allelic } \\
\text { Richness } \\
\text { (sample size } \\
\text { for rarefac- } \\
\text { tion }=25 \text { ) }\end{array}$ & $\begin{array}{l}\text { Effective } \\
\text { population } \\
\text { size Ne } \\
\text { (random) }\end{array}$ & $\begin{array}{l}\text { Effective } \\
\text { population } \\
\text { size Ne (non } \\
\text { random) }\end{array}$ \\
\hline Voigtsdorf & $\begin{array}{l}\text { GREEN1_P } \\
\text { GREEN1_- } \\
\text { F1 }\end{array}$ & $\begin{array}{l}25 \\
44\end{array}$ & $\begin{array}{l}0.71 \pm 0.04 \\
\mathrm{n} / \mathrm{a}\end{array}$ & $\begin{array}{l}0.90 \pm 0.01 \\
\mathrm{n} / \mathrm{a}\end{array}$ & $\begin{array}{l}19.89 \pm 1.81 \\
\mathrm{n} / \mathrm{a}\end{array}$ & $\begin{array}{l}11.50 \pm 1.48 \\
\mathrm{n} / \mathrm{a}\end{array}$ & $\begin{array}{l}19.89 \pm 0 \\
\text { n/a }\end{array}$ & $\mathrm{n} / \mathrm{a}$ & $\mathrm{n} / \mathrm{a}$ \\
\hline Niederfinow & $\begin{array}{l}\text { GREEN2_P } \\
\text { GREEN2_ } \\
\text { F1 }\end{array}$ & $\begin{array}{l}40 \\
281\end{array}$ & $\begin{array}{l}0.64 \pm 0.07 \\
0.66 \pm 0.07\end{array}$ & $\begin{array}{l}0.92 \pm 0.01 \\
0.91 \pm 0.01\end{array}$ & $\begin{array}{l}24.56 \pm 2.26 \\
24.67 \pm 2.69\end{array}$ & $\begin{array}{l}13.75 \pm 1.84 \\
11.79 \pm 1.31\end{array}$ & $\begin{array}{l}19.45 \pm 0.60 \\
15.36 \pm 0.69\end{array}$ & 27 & 22 \\
\hline Harsefeld & $\begin{array}{l}\text { GREEN3_P } \\
\text { GREEN3_ } \\
\text { F1 }\end{array}$ & $\begin{array}{l}115 \\
365\end{array}$ & $\begin{array}{l}0.65 \pm 0.06 \\
0.74 \pm 0.07\end{array}$ & $\begin{array}{l}0.92 \pm 0.02 \\
0.92 \pm 0.01\end{array}$ & $\begin{array}{l}32.78 \pm 3.99 \\
30.89 \pm 3.82\end{array}$ & $\begin{array}{l}14.99 \pm 2.31 \\
13.82 \pm 1.66\end{array}$ & $\begin{array}{l}18.39 \pm 0.70 \\
16.87 \pm 0.68\end{array}$ & 41 & 35 \\
\hline Beerwalde & $\begin{array}{l}\text { GREY_P } \\
\text { GREY_F1 }\end{array}$ & $\begin{array}{l}32 \\
686\end{array}$ & $\begin{array}{l}0.74 \pm 0.07 \\
0.74 \pm 0.08\end{array}$ & $\begin{array}{l}0.88 \pm 0.01 \\
0.86 \pm 0.01\end{array}$ & $\begin{array}{l}16.89 \pm 1.44 \\
18.11 \pm 1.58\end{array}$ & $\begin{array}{l}8.83 \pm 0.89 \\
7.64 \pm 0.50\end{array}$ & $\begin{array}{l}15.19 \pm 0.48 \\
11.26 \pm 0.66\end{array}$ & 13 & 12 \\
\hline
\end{tabular}

Values indicate estimated mean values \pm standard error

can cope with the existence of null alleles, allele dropouts and genotyping errors and the markers could thus be used for pedigree reconstruction without any marker corrections. The overall high values of expected heterozygosity are related to the high number of different alleles. Wojacki et al. (2019), who analysed the genetic diversity of parent and offspring individuals of four differently sized artificial Douglas fir seed stands, used an identical set of markers and found comparable levels of observed and expected heterozygosity.

The different seed orchards vary in the number of clones present in the parental generation, which seems to affect the levels of genetic diversity. When comparing the mean and effective allele numbers of the parental generations of the three different coastal Douglas fir seed orchards (SO GREEN1, GREEN2 and GREEN3), a positive relationship between the number of clones and the number of alleles can be observed (Table 4). Due to the small sample size of only three seed orchards, we refrained from a formal statistical analysis of this observation which would not be very robust and could possibly even be misleading. Estimates of allelic richness corrected for sample size are more or less on the same level for e.g. SO GREEN1 and GREEN2, indicating that the increase in allele number between these two seed orchards is indeed based on the number of clones and not on a generally higher genetic diversity.

While allele number generally increases with clone number, this does not seem to be a linear relationship. In the largest seed orchard (SO GREEN3), allele numbers are lower than would be expected under a linear model. Such a saturation effect is in agreement with several studies demonstrating that fairly small sample sizes are sufficient to represent a large proportion of the total allelic diversity within a population (Hale et al. 2012; Hoban and Schlarbaum 2014). In German seed stands analysed by Wojacki et al. (2019), the authors observed a similar relationship between population size and allele numbers, reaching a plateau with increasing population size.

However, the degree of relatedness between the parental clones also seems to impact the level of genetic diversity. This makes sense as related individuals draw from the same gene pool, and even a larger number of related individuals might only represent a limited level of genetic diversity. Therefore, the potentially higher degree of relatedness among the 115 parental clones possibly also contributes to the only slight increase in allele numbers in SO GREEN3.

The parental generation of the "grey" Douglas fir seed orchard shows comparably low allele numbers. Allelic richness corrected for sample size is considerably lower than in the seed orchards of the green variety. This is probably caused by the high degree of relatedness among the clones of the seed orchard. It is possible, however, that genetic diversity is generally lower in "grey" than in coastal "green" Douglas fir. Since only one "grey" and three "green" seed orchards have been studied, the latter additionally originating from the same region, this cannot be answered by our data. Moreover, given the lower genetic diversity that has been observed in SO GREY, the resulting potential lack of marker resolution could somewhat inflate the detected degree of relationship and must be regarded with caution.

Generally, genetic diversity within seed orchards seemingly rises with the number of clones and decreases with increasing relatedness. 


\section{Transfer of genetic diversity to the next generation}

The preservation of genetic diversity between succeeding generations within seed-orchards is affected by several independent factors: selfing, pollen contamination, and reproductive bias.

\section{Selfing}

Generally, selfing and mating between relatives should be minimized, since it facilitates inbreeding depression and the loss of genetic diversity. Seed orchard design aims to reduce selfing and mating between relatives by using a repeated and randomised layout of (ideally unrelated) clones.

Within the analysed seed orchards, selfing rates were low and varied between 0.82 and 1.9\% (Table 3). Despite comparable clone/individual numbers, selfing rates in the different seed stand analysed by Wojacki et al. (2019) were higher and varied between 1.3 and $12.7 \%$. Apparently, the repeated and randomised layout of the clones in the seed orchard combined with a high total number of trees and pollen production succeeds in fostering more effective cross-pollination between all clones.

In accordance with these results, Slavov et al. (2005) also reported low levels of selfing ranging from 1 to $2.3 \%$ in a non-isolated open-pollinated Douglas fir seed orchard, located in Oregon, USA. However, within a Canadian seed orchard, higher selfing rates ranging from 12 to $17 \%$ were observed (El-Kassaby et al. 2010; Kess and El-Kassaby 2015; Korecky and El-Kassaby 2016; Lai et al. 2010; Song et al. 2018). These were explained by strong female fertility variation and a strong correlation between female reproductive success and selfing rate (El-Kassaby et al. 2010).

The seed orchards analysed here seem to show a negative relationship between selfing rate and clone number (Table 3). The already low selfing rates thus further decrease with increasing clone number. As explained with the relationship between clone number and allele number, we refrained from a formal statistical analysis due to the small sample size. However, Wojacki et al. (2019) also observed a similar correlation between stand size and selfing rates. Thus, a higher number of clones within seed orchards will not only influence genetic diversity through higher allele numbers but also decrease selfing and thus promote a better transfer of genetic diversity to the next generation.

Future research on a broader range of different seed orchards could help in quantifying the effect of clone number and relatedness on genetic diversity and selfing rates and would be helpful in obtaining robust estimates on minimum clone numbers in seed orchard design.

\section{Pollen contamination}

Pollen contamination from outside of the seed orchard can increase genetic diversity, but also potentially leads to the introduction of inferior genetic material and should thus be prevented. This aim is normally achieved by spatial isolation of the seed orchard from populations of the same species.

Pollen contamination levels within the analysed seed orchards were low and varied between 0.58 and $8.49 \%$ (Table 3). This indicates a desirable high level of spatial genetic isolation of the seed orchards preventing the introduction of large amounts of genetic material from unknown sources.

Comparing pollen contamination rates between different studies can be difficult since contamination levels can be influenced by marker and parentage analysis (Funda et al. 2015). However, compared to the seed orchards analysed here, pollen contamination within the North American Douglas fir seed orchards was much higher. Slavov et al. (2005) report pollen contamination rates ranging from 31 to $41.3 \%$ in Oregon (USA), but this estimate does not only include pollen from outside the seed orchard but also from neighbouring blocks. For the Canadian seed orchard Kess and El-Kassaby (2015), Korecky and El-Kassaby (2016), Lai et al. (2010) and Song et al. (2018) reported contamination rates of $10-18 \%$ despite several measures taken to prevent pollen contamination, and up to $28 \%$ under natural conditions.

These considerably higher rates of pollen contamination can most likely be explained by the location of the different seed orchards. Western Canada and Oregon belong to the natural distribution area of Douglas fir, while introduced Douglas fir covers only about $2 \%$ of the German forest areas. A high degree of spatial isolation from other Douglas fir trees is, therefore, easier to achieve in Germany.

\section{Relative parental contributions}

From a population genetic point of view, the equal participation in reproduction of all parent clones in a seed orchard is desirable in order to effectively transfer a high number of alleles and therefore a maximum of genetic diversity from the adult to the offspring generation (Funda et al. 2009). A low number of parents involved in reproduction and high selfing rates result in a higher degree of relatedness among the offspring individuals and, hence, to a decrease in allele numbers and effective population size.

In the seed orchards analysed here, not all adult clones contributed as parents to the analysed offspring individuals (Table 5). Between 9.4 and $23.5 \%$ of adult clones have neither been sampled as seed parents nor did they contribute any pollen to the analysed offspring individuals. For a more detailed view on the participation of individual clones, the 
Table 5 Participation of adult clones in reproduction

\begin{tabular}{|c|c|c|c|c|c|c|c|}
\hline \multirow[t]{2}{*}{ Seed orchard } & \multirow[t]{2}{*}{ Location } & \multirow[t]{2}{*}{$\begin{array}{l}\text { No. of adult } \\
\text { clones }\end{array}$} & \multicolumn{2}{|c|}{$\begin{array}{l}\text { Involved in repro- } \\
\text { duction }\end{array}$} & \multicolumn{2}{|c|}{$\begin{array}{l}\text { Not involved in } \\
\text { reproduction }\end{array}$} & \multirow{2}{*}{$\begin{array}{l}\text { No. of } \\
\text { reconstructed } \\
\text { parents }\end{array}$} \\
\hline & & & Absolute & $\%$ & Absolute & $\%$ & \\
\hline GREEN2 & Niederfinow & 40 & 34 & 85.0 & 6 & 15.0 & 3 \\
\hline GREEN3 & Harsefeld & 115 & 88 & 76.5 & 27 & 23.5 & 11 \\
\hline GREY & Beerwalde & 32 & 29 & 90.6 & 3 & 9.4 & 2 \\
\hline
\end{tabular}

contribution of the individual clones to gamete (ovule and pollen) production (gametic contribution) was determined (Fig. 2A). For both seed orchards with single tree harvests (SO GREEN2 and 387 seeds of SO GREY), mother (seed parent) and father (pollen parent) of each analysed seed could be identified and the frequencies of paternal reproduction success were determined (Fig. 2B). Detailed mating schemes for these two seed orchards are shown in Figs. 3 and 4 .

Strongly uneven distribution of the contributions of the individual parent clones to the analysed offspring generation can be observed for all analysed seed orchards, culminating in the total exclusion of certain parent clones. This uneven distribution of parental contributions is caused by several factors, which will be further discussed in the following paragraphs.

\section{Sampling bias}

During seed collection, not all clones were evenly sampled, leading to overrepresentation of the clones used as seed parents. For some seed orchards, planting schemes were missing (SO GREY) or inaccurate. This led to the omission of some and a repeated sampling of other clones, rendering a systematic sampling of all clones during manual seed collection impossible. In the most extreme case (SO GREY), only $56 \%$ of the clones present were actually sampled. Additionally, in some trees, cones were without reach during sampling.

For SO GREEN3 and 299 seeds of SO GREY, seedlings/seeds originated from a mixed seed lot of a commercial harvest. Commercial harvest teams tend to focus on those trees with the highest number of cones, potentially leading to uneven representation of the different clones within the seed lot. If clones are planted in different numbers of ramets, the prob-
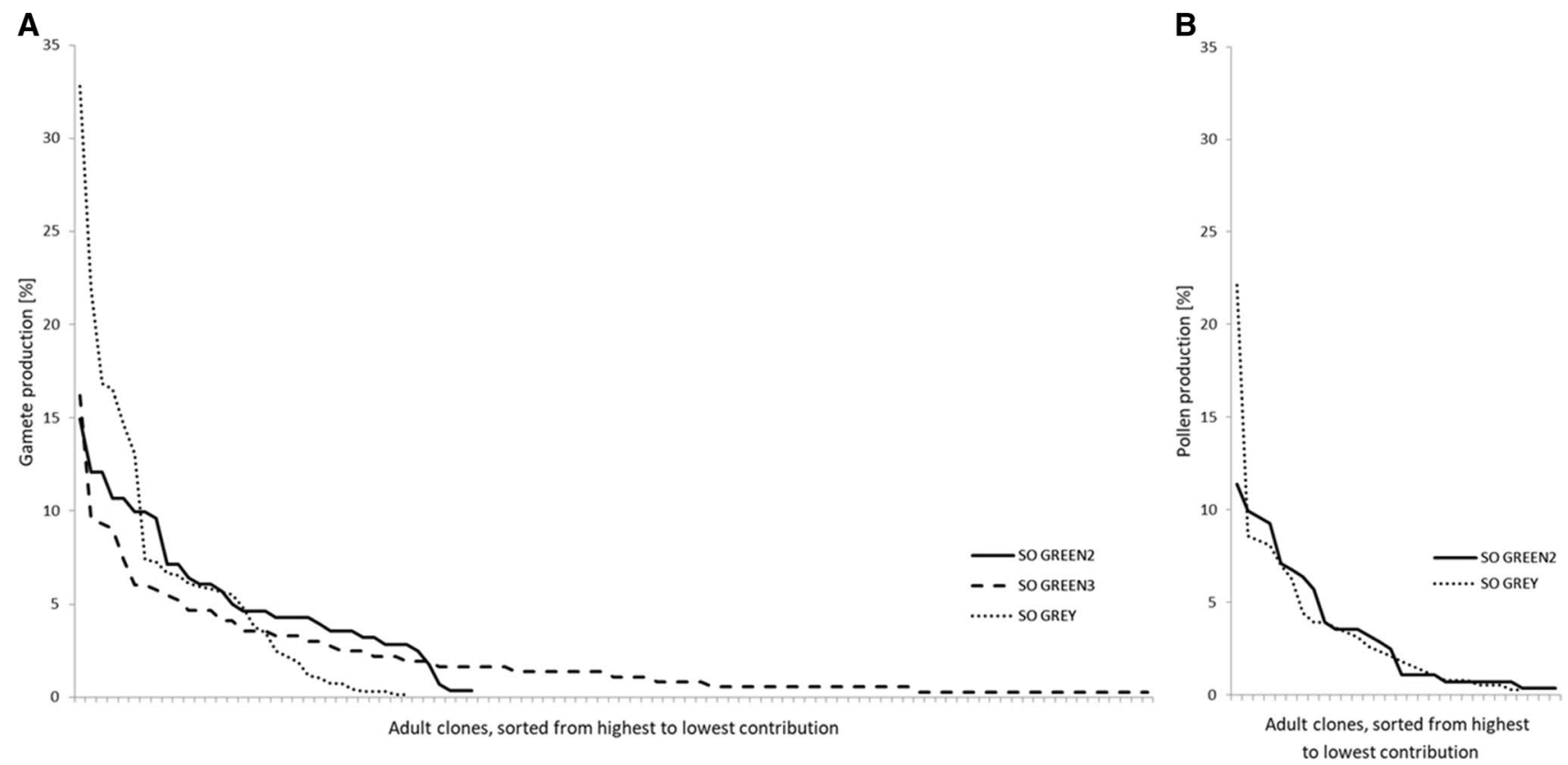

Fig. 2 Graphic display of the share of the individual parent clones in gamete (A) and pollen production (B), units on the $x$ axis represent individual clones of the seed orchards sorted from highest to lowest contribution 


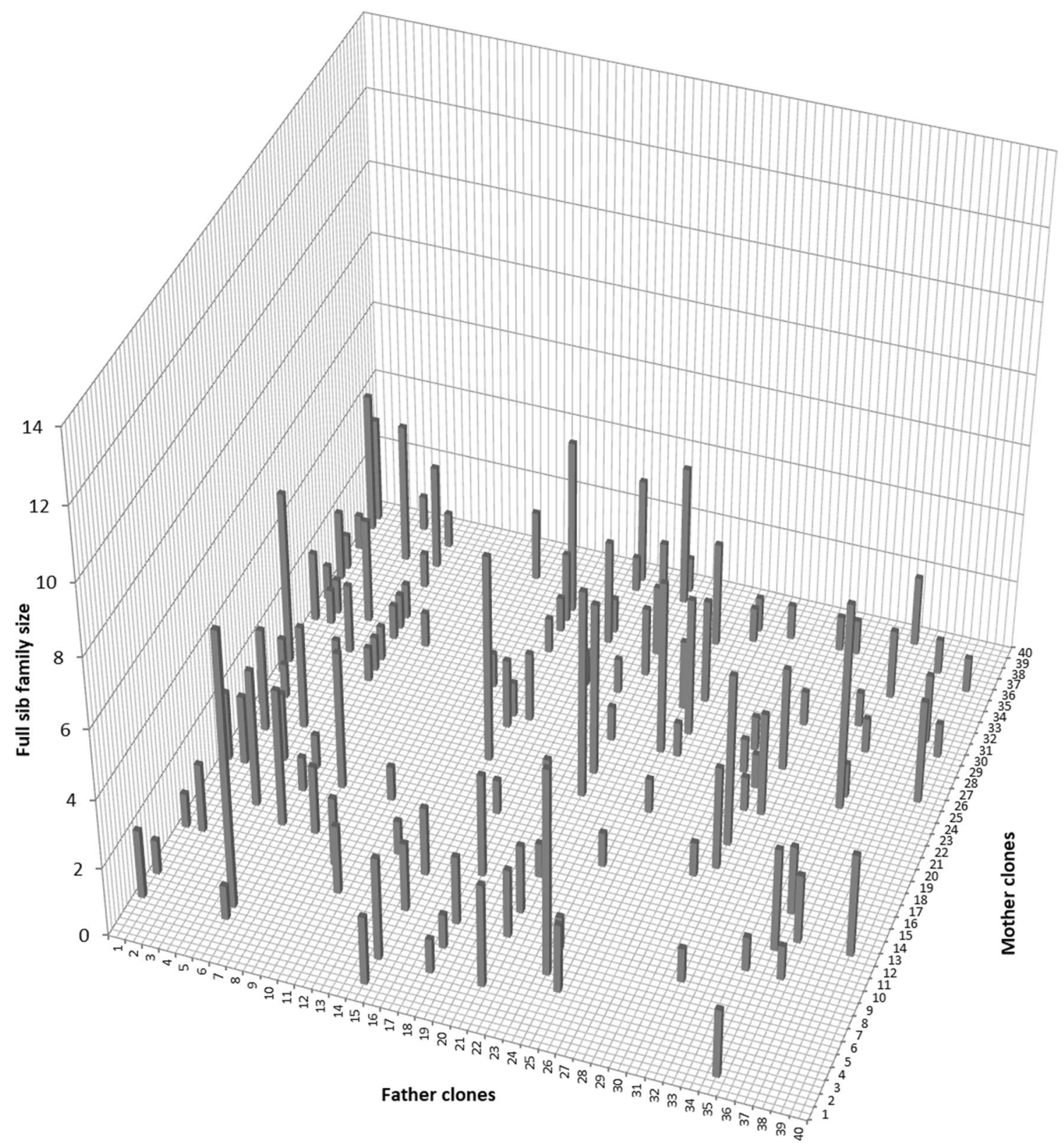

Fig. 3 3D display of mating scheme, seed orchard (SO GREEN2)

ability that clones with a higher ramet number are harvested as seed parents during a commercial harvest increases.

\section{Short-distance pollination}

The analysis of paternal reproduction success (Fig. 2) can to some degree compensate the bias introduced by the uneven sampling of seed parents since it only includes the rates of how often the different adult clones serve as pollen donors for the production of the analysed offspring. Pollen contribution rates also show an uneven distribution for both analysed seed orchards. However, trees that are sampled as seed parents are often pollinated by trees/clones growing nearby, which are then overrepresented themselves. In Douglas fir, pollination mainly by closely located neighbouring trees was observed by Wojacki et al. (2019) and Burczyk and Prat (1997). Depending on the planting scheme, tree mortality, and selection of trees to harvest, short-distance pollination can therefore also introduce a bias in the representation of different clones in the seed lot. 
Fig. 4 3D display of mating scheme, seed orchard (SO GREY) offspring from single tree harvest only

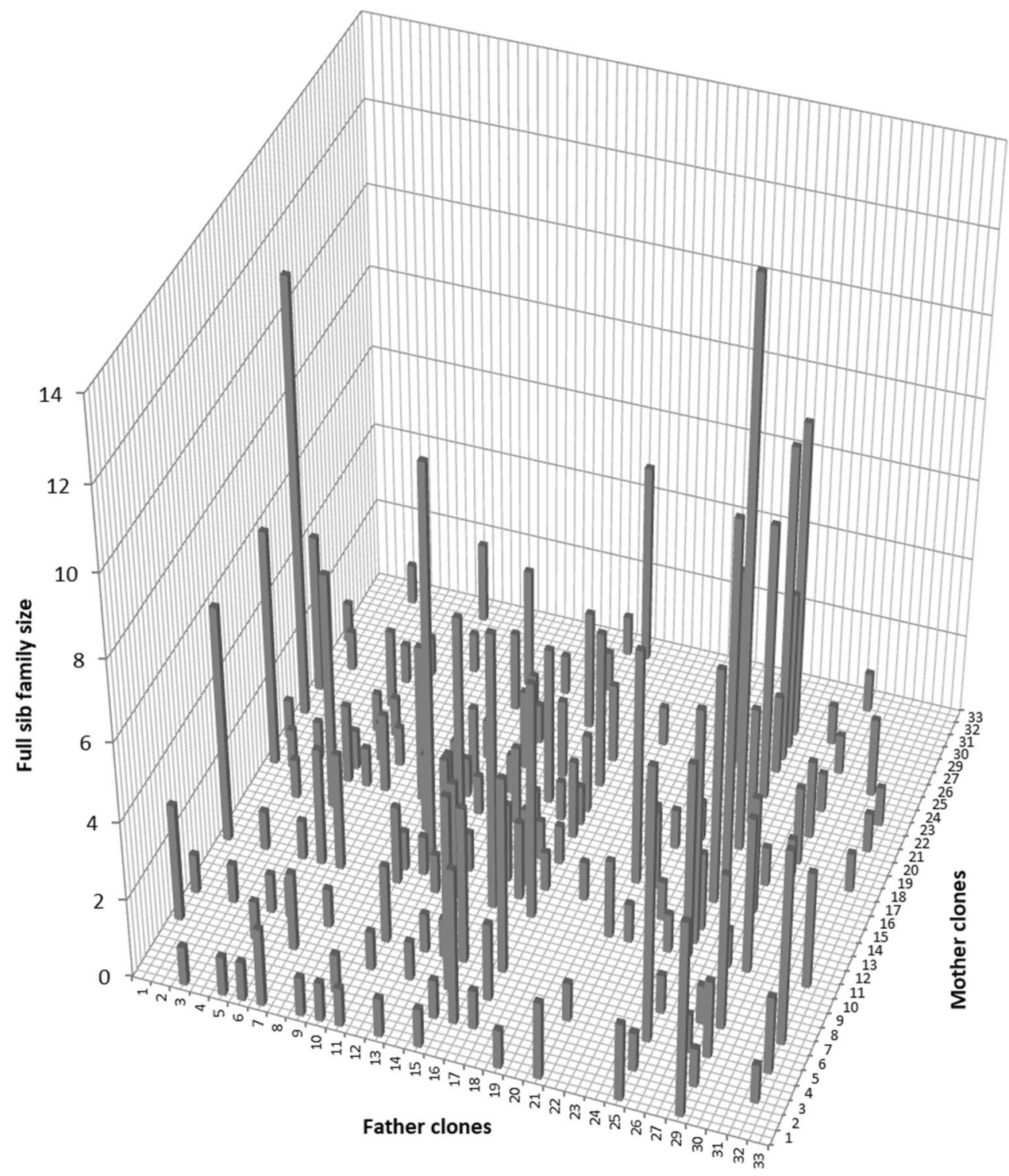

\section{Clonal representation}

Large differences in the number of ramets per clone were observed in all analysed seed orchards: 3-19 (SO GREEN2), 1-7 (SO GREEN3), 1-18 (SO GREY).

Differences in individual clonal representation are expected to affect the total pollen production per clone and hence the reproductive impact of different clones. Such a relationship has been observed by Slavov et al. (2005). On the other hand, El-Kassaby et al. (2010) and Funda et al. (2011) demonstrated, that ramet number does not necessarily increase reproductive impact. Figs. 5 and 6 show the relative contribution of pollen against the number of ramets for all clones in SO GREEN2 and SO GREY. The data shows strong variation and while there seems to be a positive relationship, it is a weak one and does not reach statisti-

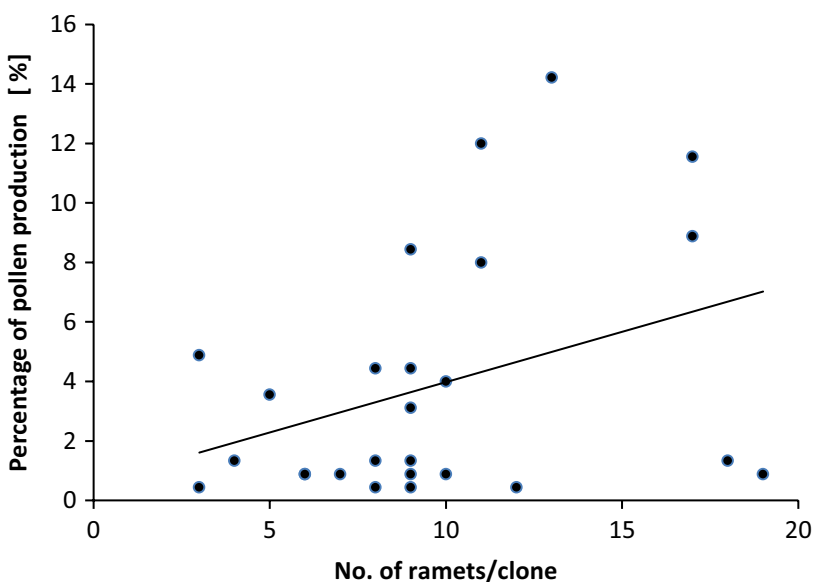

Fig. 5 SO GREEN2, number of ramets per clone plotted against percentage of successful pollen 


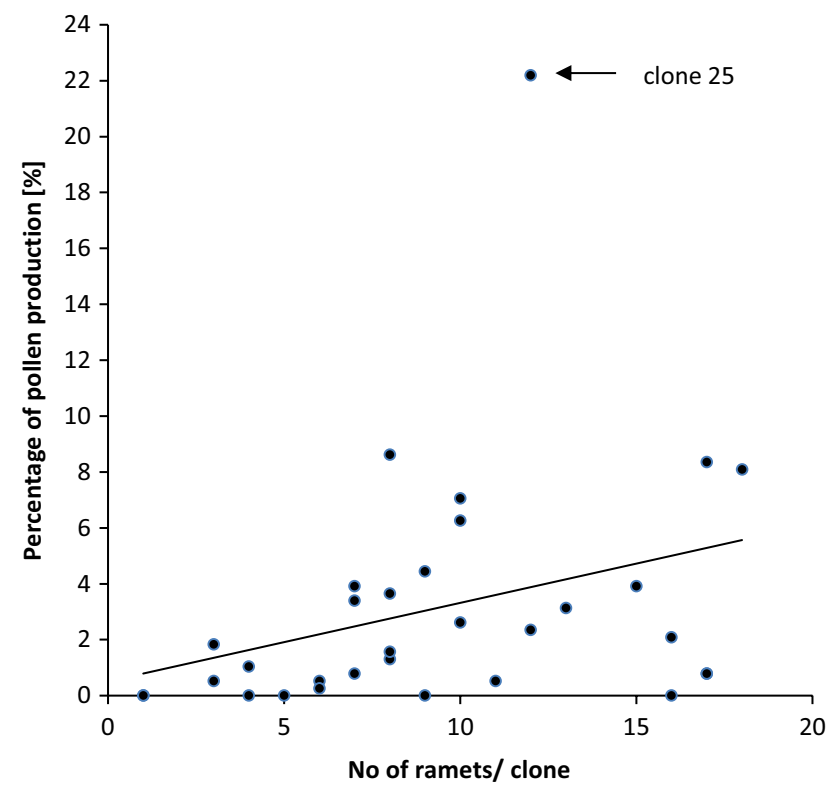

Fig. 6 SO GREY, number of ramets per clone plotted against percentage of successful pollen

cal significance in our seed orchards (linear regression; $R^{2}=0.091, p$-value $=0.073$ in SO GREEN2; $R^{2}=0.069, p$-value $=0.079$ in SO GREY). Therefore, while the number of ramets might increase reproductive impact of a clone, this relationship might be cofounded by additional factors (e.g., variation in individual fertility, flowering time, genetic compatibility between clones) and apparently cannot be taken for granted under all circumstances.

\section{Fertility and other factors}

Not all clones with a high number of ramets show a high share in pollen production, possibly due to low fertility of these clones. On the other hand, one single clone produced $22 \%$ of the total pollen in SO GREY, despite only a medium number of ramets (clone " 25 ", Figs. 4 and 6).

These effects again point towards the influence of other factors on a clone's relative parental contribution -either intrinsic (e.g., variation in flowering time, flowering intensity, or genetic compatibility) or environmental (e.g., wind direction or speed during flowering). In agreement with our results, El-Kassaby et al. (2010) and Funda et al. (2011) showed that the number of ramets per clone is not the most accurate model to predict reproductive success and that different levels of fertility have to be considered as well.

For a number of reasons, uneven parental contributions seem to represent the standard mating pattern found when analysing Douglas fir seed orchards. In the seed orchards analysed here, $80 \%$ of all gametes are produced by only about 52\% (SO GREEN2), 33\% (SO GREEN3) and 37\% (SO GREY) of all potential parent clones (Fig. 7). Regarding pollen production only, $80 \%$ of the pollen are produced by only about 30\% (SO GREEN2) and 40\% (SO GREEN3) of all parent clones (Fig. 7). These values of individual clonal reproductive success range at comparable levels with those reported in other studies. Similar proportions have been

Fig. 7 Reproductive success

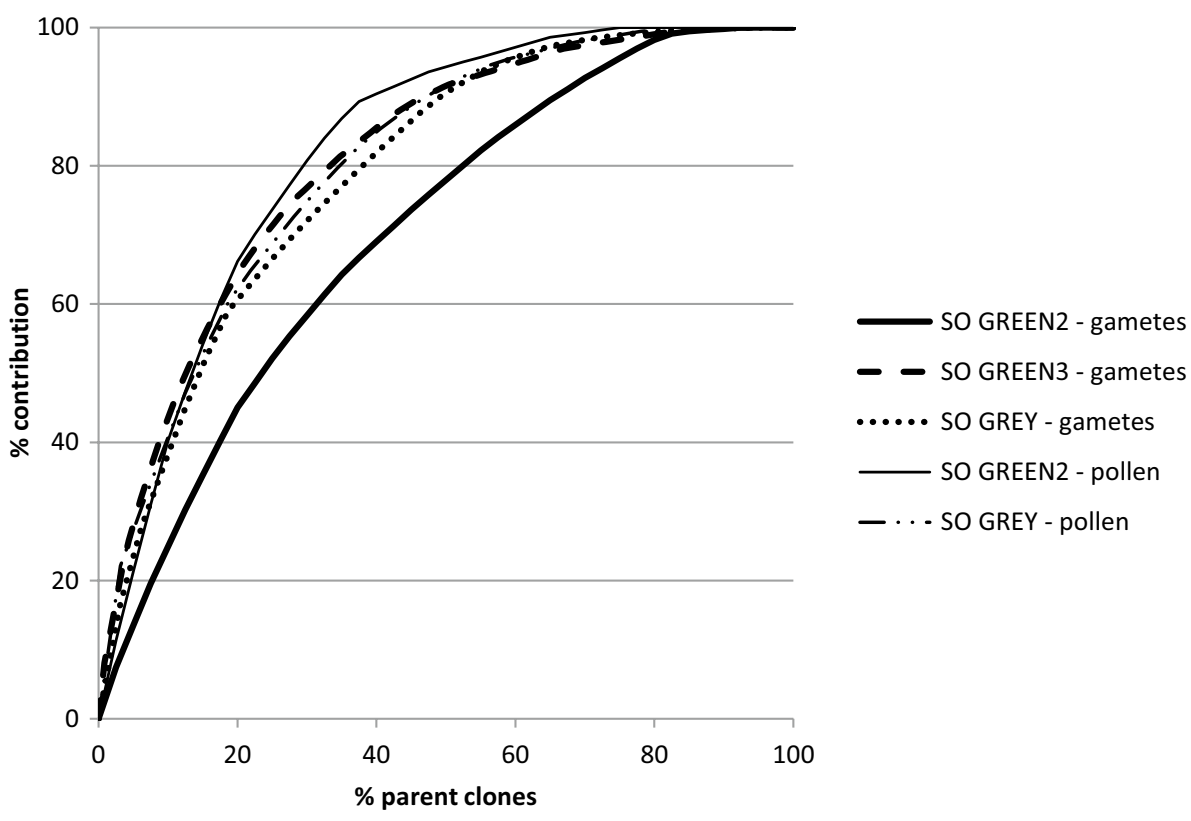


observed by Slavov et al. (2005) and persisted even when measures were taken to compensate for distorting effects during seed sampling (Kess and El-Kassaby (2015); Korecky and El-Kassaby (2016); Lai et al. (2010); Song et al. (2018)).

However, the percentage of parents successfully involved in reproduction in our study is considerably higher (76.5-90.6\%) than within the seed stands analysed by Wojacki et al. (2019) (32.8-66.3\%), indicating that the repetitive planting of several ramets per clone in planting schemes designed specifically to increase cross-pollination in seed orchards succeeds in partially compensating uneven reproductive success.

Differences in the number of ramets per clone and an unbalanced harvest of clones might cancel out this advantage. Therefore, it seems advisable to design seed orchards using equal numbers of ramets per clone, unless specific information on breeding values argues for the overrepresentation of certain clones (Lindgren and Matheson (1986). During harvest, the aim should be to collect seed from as many different seed parents as possible while maintaining a balance in the number of harvested ramets per clone.

\section{Consequences for the level of genetic diversity within the analysed offspring generations}

For the seed orchards GREEN2, GREEN3 and GREY the mean number of alleles of the offspring generation are more or less at the same level or just slightly lower as in the parental generation (Table 4). The mean number of alleles even rises slightly in the offspring generation of SO GREY, a fact that can probably be explained by the introduction of new alleles by pollination from outside of the stand, although some scoring errors due to many out-of-ladder-alleles cannot be completely ruled out. This generally speaks for a good transfer of genetic diversity to the next generation in all analysed seed orchards.

This observation, however, can be biased by the large difference in sampling size between the two generations (Table 4). In order to compensate for this potential bias, allelic richness was also calculated using rarefaction in order to take sample size differences into account (Table 4). When looking at it this way, allelic richness decreases from the parent to the offspring generation in all analysed seed orchards. This is somewhat expected as analysing parental and offspring generation together, in this case, leads to a very strong reduction in sample size for the F1 generation. Moreover, the parent generations are represented by an "optimal" cohort of different more or less unrelated individuals (each clone is included only once in each full dataset). The offspring generations, on the other hand, are represented by randomly combined individuals in diverse half- and full-sib relations, which are therefore expressing higher levels of relatedness than the parent generation. So, in this case, the calculation of allelic richness might overcompensate the differences in the levels of genetic diversity. Anyway, multiple degrees of relationship within the $\mathrm{F} 1$ generation of a seed orchard influence the level of genetic diversity when looking at a smaller subset of individuals and have to be taken into account considering the future harvest and use of seed material. Harvesting only small numbers of seeds from a small number of clones could create some kind of artificial genetic drift and lower genetic diversity within the seed lot.

Comparing the levels of allelic richness between the different F1 generations, allelic richness of the offspring generations is slightly higher in SO GREEN3 than SO GREEN2. As in the parent generation, allelic richness is lowest in SO GREY, caused by the low number and high degree of relatedness of the parent clones. This indicates that the number of parent clones plays an important role not only in the level of genetic diversity present in a seed orchard but also in the preservation of this diversity in the offspring generation.

Looking at the effective number of alleles, rare alleles are taken into account on a lesser scale. Therefore, the better preservation of rare alleles in situations with more equal participation of all parent clones in reproduction plays only a minor role for the calculation. Even when looking at absolute numbers and not correcting for different sample sizes, the effective number of alleles decreases from parental to offspring generation.

Taken together, the absolute number of alleles present in the parent generation seems to be more or less well preserved when looking at a large sample of offspring individuals. However, the offspring individuals feature multiple degrees of relationship, a fact that influences the levels of genetic diversity of smaller subsets of offspring individuals and should be kept in mind. Generally, a higher number of parent clones seems to promote genetic diversity in both the parent and the offspring generation.

Compared to these results, not only the effective but also the mean allele numbers decreased slightly from the parent to the offspring generation in German seed stands (Wojacki et al. 2019). This can be explained by the higher rates of parents not involved in reproduction and higher selfing rates. A decrease in genetic diversity from parent to offspring generation was also observed by Neophytou et al. (2020) in 36 different seed stands in Central Europe. They explained this with the fragmented and small size of European stands.

The opposite, i.e., an increase in the number of alleles in the offspring compared to the parent generation was observed in the Canadian seed orchard. This was probably caused by the high rate of pollen contamination from outside, leading to the introduction of new alleles (Kess and El-Kassaby (2015); Korecky and El-Kassaby (2016); Lai et al. (2010); Song et al. (2018)). 
These observations demonstrate that the loss of genetic diversity during harvest is a potential issue in European seed orchards as well as seed stands. This issue can be addressed, however, by ensuring high clone numbers within the parental generations, harvesting a large number of seeds and taking care to collect seed from all clones within the seed orchard. If these requirements can be met, the preservation of genetic diversity, especially of rare alleles, seems to be more reliable in seed orchards than in the comparatively small European seed stands.

\section{Conclusions}

The different seed orchards analysed here showed low pollen contamination rates, probably due to a high degree of spatial isolation. The seed orchard design with randomized and repeated planting of clones led to low selfing rates and despite uneven parental contributions, the number of successful parents and the level of genetic intermixture were high enough to allow an adequate transfer of genetic diversity to the next generation. The results of this study allow conclusions to be drawn for future seed orchard design and set up in Germany.

The aim of seed orchard design and setup is the effective production of high-quality seed. Next to traits like height, straightness and vitality, genetic diversity of parent clones should be considered in order to allow the production of adaptable future stands in times of climate change. For the conservation of genetic diversity in future offspring, the selection of genetically diverse, not too closely related parent trees is crucial for seed orchard design and setup.

Within limits, genetic diversity rises with the number of clones used for seed orchard setup. For this reason, a certain minimum number of clones is recommendable and will have additional positive effects by lowering selfing rates. Above a certain number of parental clones, saturation with no more relevant rise in allele numbers seems to occur. Based on the results of this study of four seed orchards with different clone numbers and different levels of relatedness, a precise determination of ideal clone number for the preservation of genetic diversity is not possible and would require analysing a larger number of seed orchards. Studies dealing with the optimal number of clones for seed orchard setup are rare and are not mainly dealing with the conservation of genetic diversity but also focus on different aspects like genetic gain, favouring a lower number of clones (see Lindgren and Prescher 2005 and Funda and El-Kassaby 2012). Still, it can be stated that the minimum number of clones for the conservation of genetic diversity in seed orchards can be lower than that in seed stands since the repeated and randomized planting of ramets facilitates a more balanced participation of all parent clones in reproduction, lowers selfing rates and increases the number of different parent combinations, which leads to a better transfer of genetic diversity to the offspring generation. While Wojacki et al. (2019) showed that the minimum number of 40 adult trees stated for Douglas fir in the German Act on Forest Reproductive material (Anonymous 2002a,b) is too low to prevent the loss of genetic diversity in seed stands, our results show that seed orchard setup which includes the repeated planting of 40 not closely related clones can be sufficient to capture a large part of the genetic diversity within the next generation. Larger clone numbers, however, are possibly necessary to reliably conserve a maximum of genetic diversity. Obtaining robust estimates of the minimum clone number needed to reliably transfer the genetic diversity of the seed orchard into the offspring generation would be a worthwhile goal for future studies.

To further improve the transfer of genetic diversity from parent to offspring generation, equal participation of all parent clones in reproduction should be facilitated. Especially if no information on breeding values is available, parent clones should be planted in equal ramet numbers to prevent the dominance of certain clones. The majority of pollinations occur between trees located in close proximity. For this reason, and as already incorporated into various different seed orchard designs (e.g. Chaloupková et al. 2016; Giertych 1975; Lstibůrek and El-Kassaby 2010; Van Buijtenen 1971), ramets of the same clone should be surrounded by different clones in various different combinations to increase the number of possible parent combinations.

During seed harvest, a balanced harvest of a high number of different seed parents should be carried out. If logistically possible, the collection of seeds from several ramets of every clone should be considered. These should be distributed evenly over the seed orchard. As for all other aspects of seed orchard management (White et al. 2007), the maintenance of good records and clear labelling of trees is also crucial for the optimal organisation of a balanced harvest of genetically diverse, high-quality seed lots.

Acknowledgements We would like to thank Falk Schäfer for help with the field work and the respective forest authorities and forest owners.

Authors' contributions BP analysed the data and wrote the manuscript. PE helped with sampling activities, data analysis and writing of the manuscript. JW designed and performed the sampling activities and was involved in genotype analysis. DA carried out the practical analyses in the laboratory. HL was responsible for study conception and design and contributed to data analysis. All authors commented on previous versions of the manuscript. All authors read and approved the final manuscript.

Funding Open Access funding enabled and organized by Projekt DEAL. This work was supported by Waldklimafonds as part of the project AdaptForClim (22WB415204, Federal Ministry of Food and Agriculture and Federal Ministry of Environment, Nature Conservation and Nuclear Safety). 
Availability of data and material Upon acceptance for publication of the manuscript all data on SSR genotypes will be made available on OSF (Open Science Framework, https://osf.io).

\section{Declarations}

Conflict of interest The authors have no conflicts of interest to declare that are relevant to the content of this article.

Consent to participate All authors agreed to participate in the described study.

Consent for publication All authors agreed to publish the results described in this manuscript.

Open Access This article is licensed under a Creative Commons Attribution 4.0 International License, which permits use, sharing, adaptation, distribution and reproduction in any medium or format, as long as you give appropriate credit to the original author(s) and the source, provide a link to the Creative Commons licence, and indicate if changes were made. The images or other third party material in this article are included in the article's Creative Commons licence, unless indicated otherwise in a credit line to the material. If material is not included in the article's Creative Commons licence and your intended use is not permitted by statutory regulation or exceeds the permitted use, you will need to obtain permission directly from the copyright holder. To view a copy of this licence, visit http://creativecommons.org/licenses/by/4.0/.

\section{References}

Anonymous (2002a) Forstvermehrungs-Zulassungsverordnung (FoVZV). BGBI I 88:4721-4729

Anonymous (2002b) Forstvermehrunsggutgesetz (FoVG). BGBI I $32: 1658-1666$

Anonymous (2021) Versorgungsbilanz für forstliches Saatgut unterteilt nach Baumarten (https://fgrdeu.genres.de/index.php?id= 1606\&L=0), Bundesanstalt für Landwirtschaft und Ernährung (Federal Agency for Agriculture and Food), ed

Burczyk J, Prat D (1997) Male reproductive success in Pseudotsuga menziesii (Mirb.) Franco: the effects of spatial structure and flowering characteristics. Heredity 79:638-647

Chaloupková K, Stejskal J, El-Kassaby YA, Lstibůrek M (2016) Optimum neighborhood seed orchard design. Tree Genetics Genomes $12: 1-7$

Dumolin S, Demesure B, Petit R (1995) Inheritance of chloroplast and mitochondrial genomes in pedunculate oak investigated with an efficient PCR method. Theor Appl Genet 91:1253-1256

Earl DA (2012) STRUCTURE HARVESTER: a website and program for visualizing STRUCTURE output and implementing the Evanno method. Conserv Genet Resour 4:359-361

Funda T, El-Kassaby Y (2012) Seed orchard genetics. CAB Reviews Perspectives in Agriculture Veterinary Science Nutrition and Natural Resources 7

El-Kassaby, Y.A., Funda, T., Lai, B.S (2010) Female reproductive success variation in a Pseudotsuga menziesii seed orchard as revealed by pedigree reconstruction from a bulk seed collection. J Hered 101:164-168

Evanno G, Regnaut S, Goudet J (2005) Detecting the number of clusters of individuals using the software STRUCTURE: a simulation study. Mol Ecol 14:2611-2620
Funda T, Liewlaksaneeyanawin C, Fundova I, Lai BS, Walsh C, Van Niejenhuis A, Cook C, Graham H, Woods J. El-Kassaby YA (2011) Congruence between parental reproductive investment and success determined by DNA-based pedigree reconstruction in conifer seed orchards. Canadian Journal of Forest Research 41:380-389

Funda, T., Lstibůrek, M., Lachout, P., Klápště, J., El-Kassaby, Y (2009) Optimization of combined genetic gain and diversity for collection and deployment of seed orchard crops. Tree Genet Genomes 5:583-593

Funda, T., Wennström, U., Almqvist, C., Torimaru, T., Gull, B.A., Wang, X.-R (2015) Low rates of pollen contamination in a Scots pine seed orchard in Sweden: the exception or the norm? Scand $\mathrm{J}$ for Res 30:573-586

Giertych M (1975) Seed orchard designs. In Seed orchards (Forestry Commission, Bulletin), pp 25-37

Hale ML, Burg TM, Steeves TEJPo (2012) Sampling for microsatellitebased population genetic studies: 25 to 30 individuals per population is enough to accurately estimate allele frequencies. PLoS ONE 7:e45170

Harrison HB, Saenz-Agudelo P, Planes S, Jones GP, Berumen ML (2013) Relative accuracy of three common methods of parentage analysis in natural populations. Mol Ecol 22:1158-1170

Hoban S, Schlarbaum S (2014) Optimal sampling of seeds from plant populations for ex-situ conservation of genetic biodiversity, considering realistic population structure. Biol Cons 177:90-99

Ingvarsson PK, Dahlberg H (2019) The effects of clonal forestry on genetic diversity in wild and domesticated stands of forest trees. Scand J for Res 34:370-379

Ivetic V, Devetakovic J, Nonic M, Stankovic D, Sijacic-Nikolic M (2016) Genetic diversity and forest reproductive materialfrom seed source selection to planting. iForest-Biogeosci For 9:801-812

Jones OR, Wang J (2010) COLONY: a program for parentage and sibship inference from multilocus genotype data. Mol Ecol Resour 10:551-555

Kalinowski ST, Taper ML, Marshall TC (2007) Revising how the computer program CERVUS accommodates genotyping error increases success in paternity assignment. Mol Ecol 16:1099-1106

Kess T, El-Kassaby YA (2015) Estimates of pollen contamination and selfing in a coastal Douglas-fir seed orchard. Scand J for Res 30:266-275

Kleinschmit J, Bastien J (1992) IUFRO's role in Douglas-fir (Pseudotsuga menziesii (Mirb.) Franco) tree improvement. Silvae Genetica 41:161-173

Kopelman NM, Mayzel J, Jakobsson M, Rosenberg NA, Mayrose I (2015) Clumpak: a program for identifying clustering modes and packaging population structure inferences across K. Mol Ecol Resour 15:1179-1191

Korecky J, El-Kassaby Y (2016) Pollination dynamics variation in a Douglas-fir seed orchard as revealed by microsatellite analysis. Silva Fennica 50

Lai, B.S., Funda, T., Liewlaksaneeyanawin, C., Klápště, J., Van Niejenhuis, A., Cook, C., Stoehr, M.U., Woods, J., and El-Kassaby, Y.A (2010) Pollination dynamics in a Douglas-fir seed orchard as revealed by pedigree reconstruction. Ann for Sci 67:808-808

Lavender DP, Hermann RK (2014) Douglas-fir: the genus Pseudotsuga

Liesebach H, Liepe K, Bäucker C (2021) Towards new seed orchard designs in Germany - A review. Silvae Genetica 70:84-98

Lindgren D, Matheson A (1986) An algorithm for increasing the genetic quality of seed from seed orchards by using the better clones in higher proportions. Silvae Genetica 35:173-177

Lindgren D, Prescher F (2005) Optimal clone number for seed orchards with tested clones. Silvae Genetica 54:80-92 
Lstibůrek M, El-Kassaby YA (2010) Minimum-inbreeding seed orchard design. Forest Science 56:603-608

Marshall T, Slate J, Kruuk L, Pemberton J (1998) Statistical confidence for likelihood-based paternity inference in natural populations. Mol Ecol 7:639-655

Neophytou C, van Loo M, Hasenauer H (2020) Genetic diversity in introduced Douglas-fir and its natural regeneration in Central Europe. Forestry Int J For Res 93:535-544

Peakall R, Smouse PE (2012) GenAlEx 6.5: genetic analysis in Excel. Population genetic software for teaching and research—an update. Bioinformatics 28:2537-2539

Pritchard JK, Stephens M, Donnelly P (2000) Inference of Population Structure Using Multilocus Genotype Data. Genetics 155:945

Rau H-M (2005) Der internationale Douglasien-Provenienzversuch in Hessen-Ergebnisse bis zum Alter 27. Forst Und Holz 60:291-294

RCoreTeam (2013) R: a language and environment for statistical computing

Riedel T, Henning P, Kroiher F, Polley H, Schmitz F, Schwitzgebel F (2017) Bundeswaldinventur (BWI 2012) Inventur und Auswertemethoden 1-124

Slavov GT, Howe GT, Yakovlev I, Edwards KJ, Krutovskii KV, Tuskan GA, Carlson JE, Strauss SH, Adams WT (2004) Highly variable SSR markers in Douglas-fir: Mendelian inheritance and map locations. Theor Appl Genet 108:873-880

Slavov G, Howe G, Adams W (2005) Pollen contamination and mating patterns in a Douglas-fir seed orchard as measured by simple sequence repeat markers. Can J for Res 35:1592-1603
Song J, Ratcliffe B, Kess T, Lai BS, Korecký J, El-Kassaby YA (2018) Temporal quantification of mating system parameters in a coastal Douglas-fir seed orchard under manipulated pollination environment. Sci Rep 8:1-6

Spellmann H, Weller A, Brang P, Michiels H-G, Bolte AT (2015) Douglasie (Pseudotsuga menziesii (Mirb.) Franco) in Potenziale und Risiken eingeführter Baumarten. Universitätsverlag Göttingen, Göttingen

Van Buijtenen J (1971) Seed orchard design, theory and practice. Paper presented at: Southern Conf Forest Tree Impr Proc

Weller A, Jansen M (2017) Internationale Douglasien-Provenienzversuchsserie von 1961: Vergleich ausgewählter Herkünfte auf Basis von Oberhöhenleistung und Rangveränderungen bis Alter 58 Jahre. Forstarchiv 88:3-16

White TL, Adams WT, Neale DB (2007) Forest Genetics (Cabi)

Wojacki J, Eusemann P, Ahnert D, Pakull B, Liesebach H (2019) Genetic diversity in seeds produced in artificial Douglas-fir (Pseudotsuga menziesii) stands of different size. For Ecol Manage 438:18-24

Woods JH, Heaman JC (1989) Effect of different inbreeding levels on filled seed production in Douglas-fir. Can J for Res 19:54-59

Publisher's Note Springer Nature remains neutral with regard to jurisdictional claims in published maps and institutional affiliations. 